\title{
A RECUSA DE UMA RELAÇÃO DE DETERMINAÇÃO NAS INVESTIGAÇÕES FILOSÓFICAS
}

\author{
Raphaela Silva de Oliveira \\ Universidade Ferderal de São Paulo \\ Mestranda
}

\section{Resumo:}

Pretendo expor panoramicamente, a partir da apresentação da leitura dos parágrafos 134 a 155 das Investigações Filosóficas, a problemática abordada em meu projeto de mestrado, que trata de como nos parágrafos anteriores a usual delimitação do famoso debate sobre "seguir regras", de 192 a 242, Wittgenstein já elabora uma recusa da relação de determinação a partir na investigação do termo "verstehen" (entender). Nesse debate, Wittgenstein nos esclarece como o "uso" não está determinado pela "regra", ou melhor, não está contida na regra a ação que eu preciso realizar: quando estou diante da regra " +2 " é simplesmente uma prática em que fui treinado que me impele a segui a série " $2,4,6,8 \ldots$..", não a própria regra. Nos parágrafos que me proponho a analisar nessa comunicação, Wittgenstein expõe como o emprego de uma proposição e a aplicação de uma fórmula não necessitam pressupor uma relação de determinação para serem entendidos. A compreensão não depende de uma regra que determine o que está contido na proposição para que eu possa pegar as expressões que tenho disponível e ajustá-las a um emprego, nem que determine a aplicação de uma fórmula de maneira que eu só possa pensar em uma aplicação particular. Para Wittgenstein, são as circunstâncias sob as quais temos uma experiência, o emprego de uma sentença ordinária ou ser guiado para seguir uma série, que garantem dizermos nesses casos que entendemos.

Palavras-chave: Investigações; regras; determinação 


\section{A recusa de uma relação de determinação}

\section{O emprego da linguagem}

Dentre os parágrafos que nos propomos a analisar, de 134 a 155, somos duas vezes convidados à investigação:

"Let's examine the sentence "This is how things are" (PI, 134).

"Let's now examine the following kind of language-game: when A gives an order, B has to write down series of signs according to a certain formation rule" (PI, 143).

Em ambos, a proposta de uma investigação aparece atrelada a uma preocupação em como a linguagem é empregada. No caso do parágrafo 134, Wittgenstein chega à conclusão de que no Tractatus, sua primeira obra, a sentença considerada forma geral da proposição, "As coisas são assim", era usada como esquema, "mas somente porque tinhas a construção de uma frase em inglês", ou melhor, é antes o uso cotidiano da frase "As coisas são assim”, como quando alguém "explica a sua situação para mim, diz que as coisas são de tal maneira que ele precisa de um adiantamento", por exemplo, que permite no contexto do Tractatus que ela seja usada como esquema. Assim não há nada na sentença ordinária "As coisas são assim" que determine seu uso como esquema, mas é a maneira como essa sentença é empregada que permite que a identifiquemos, no caso do Tractatus, como esquema. Agora no parágrafo 143, somos novamente convidados à investigação, mas agora sobre um tipo de jogo de linguagem: "Quando A dá uma ordem, B escreve uma série de sinais de acordo com uma certa regra de formulação." Nas Investigações é constante a explicitação de um quadro cotidiano antes que Wittgenstein aborde o objeto da investigação, antes de A pedir a $\mathrm{B}$ que escreva uma série de sinais, parafraseando a obra, primeiro se requere de B que copie a série para que ele possa entender o sistema, a possibilidade de compreensão depende que B possa continuar a série sozinho. Então B escreve a série de números naturais, comete erros sistemáticos ou aleatórios. Pode haver um momento "em que a habilidade do aluno de aprender chegue ao fim." Como essa afirmação, Wittgenstein diz querer apenas mudar nossa forma de olhar as coisas, nos deixando abertos para considerar diferentes casos. Mas então, B escreve a série de 0 a 9, "para nossa satisfação" (145), ou seja, não frustrando nossas expectativas como quando apresentou a limitação do aluno em 144, 
mas o importante é notar que depende da reação do aluno a abordagem do professor, as ênfases na unidade ou na dezena no momento do aprendizado, etc. E depois de todos os esforços, ele aprende e continua a série corretamente. É importante notar que a explicação não é suficiente para a compreensão do aluno, depende da reação dele, do emprego que ele faz: O aluno é guiado pelo professor e chega um ponto em que ele prossegue sozinho, não porque a explicação determine a reação do aluno, mas porque em um certo momento ele emprega e série de acordo com o contexto.

\section{Primeiro questionamento}

Voltando à investigação de 134, questiona o interlocutor no parágrafo 135: não temos um conceito de proposição ${ }^{1}$ ? No Tractatus, segundo Wittgenstein, o conceito de uma proposição é o de que ela é qualquer coisa que pode ser verdadeiro ou falso, ou melhor, há uma "regra": o que pode ser perguntado verdadeiro ou falso. E isso que pode ser chamado verdadeiro ou falso, a proposição é o que se ajusta a "regra". Wittgenstein recusa essa imagem, porque a proposição aparece determinada (sentido lato) por regras de construção sentencial e não apenas evidenciando seu uso: em vez de simplesmente jogarmos um jogo em que o rei é colocado em cheque, criamos a complicada concepção em que o rei do xadrez é "determinado" pela sua possibilidade de ser colocado em cheque. Não obstante, no parágrafo 137, Wittgenstein parece abrir uma série de concessões ao interlocutor sobre a concepção de ajuste: 1. conseguimos ajustar o sujeito de uma frase a questão "Quem ou o que..."; 2. nós descobrirmos que letra do alfabeto vem depois do K no mesmo sentido que descobrimos o sujeito; 3. no sentido em que ajustamos o "L" como letra subseqüente, podemos aprender a distinguir entre uma proposição de outras expressões ajustando-a ao verdadeiro e ao falso. Mas em que sentido? No parágrafo seguinte, Wittgenstein admite falar-se em ajuste quando falamos no uso que fazemos das palavras: eu posso dizer que o significado de uma palavra se ajusta ao significado de outra. O problema com o uso de uma palavra é sempre o seu distanciamento do emprego cotidiano da linguagem: não há problema em dizer que algumas coisas se "ajustam" e que "as coisas são assim”, mas não se pode pretender determinar todo o uso com essas expressões. Não há precedência da verdade ou falsidade à proposição e ser colocado em cheque não antecede o rei, isso é uma

\footnotetext{
${ }^{1}$ Quando questionado, Wittgenstein responde que esse conceito são os exemplos que damos a uma pessoa que nos pergunta sobre ele. (cf. PI, § 135).

${ }^{2}$ Wittgenstein não usa a palavra determinação, é como se a ação fosse intrínseca à palavra, como e a ação já estivesse determinada pelo conceito.
} 
característica. Eu só posso ajustar um uso a partir do conhecimento do seu emprego. O "significado é o uso que fazemos da palavra, não faz sentido falar em ajuste" (138) do significado de uma palavra que eu entendo ${ }^{3}$ ao sentido da proposição que eu entendo.

A afirmação de que não podemos determinar todo o uso não deixa de passar por uma análise mais meticulosa do autor, uma questão é levantada: se o significado é o uso, e esse se dá no tempo, então, o que acontece quando ouvimos a palavra cubo (139) e sabemos o que significa (de um golpe)? Todo o uso vem antes a minha mente? Pensando assim, vemos o uso como determinado pela palavra, ouvimos "cube" e então, todo o uso está determinado. Não obstante, essa determinação entre palavra e uso é bilateral, se de um lado a palavra poderia "determinar" ${ }^{4}$ o uso, o uso poderia “determinar" a palavra e essas formas de determinar poderiam entrar em conflito quando tentamos ajustar uma a outra, então, poderíamos falhar quando acreditamos estar alcançando a palavra de um golpe. Wittgenstein introduz a concepção de imagem para mostrar o que poderia ajustar ${ }^{5}$ um uso: quando ouvimos "cubo" todo o uso está determinado, como se tivéssemos uma imagem de todo o uso previamente em nossa mente, e essa imagem falharia em se ajustar a um uso, por exemplo, quando aparece para mim um prisma e me ocorre dizer cubo. A relação de determinação preveria uma única aplicação da palavra cubo, mas o autor sugere, primeiramente, como resposta a possibilidade do erro, a aplicação de um método de projeção que não se ajusta (prisma). Mas a natureza do erro (140), como afirmará Wittgenstein, é apensar que a imagem força uma aplicação particular do uso (cubo ou prisma). Ou melhor, o erro consiste na crença de que um único caso e não outro ocorre para nós (no momento em que alcançamos, ou acreditamos alcançar, o significado). "O que é essencial agora é ver que a mesma coisa pode estar em nossas mentes quando ouvimos a palavra e ainda a aplicação ser diferente." Então, não poderíamos dizer, sugerindo uma relação de determinação, que um método particular aparece antes em minha mente, na medida em que a imagem não força a aplicação particular do uso, pois é possível imaginar diferentes aplicações de um mesmo método de projeção de um cubo (141).

\footnotetext{
${ }^{3}$ Toda essa análise, gradativamente, vai se revelando um preâmbulo para a investigação do termo chave para a compreensão da recusa da relação de determinação, o termo "verstehen" (entender).

${ }^{4}$ Aqui é o autor que fala em determinação.

${ }^{5}$ Bem como no caso do conceito de proposição (135-6), dada uma "regra" que determina sua aplicação, Wittgenstein problematiza a concepção de ajuste que aparece subentendida na dinâmica dessa regra.
} 


\section{Segundo questionamento}

Então, o aluno aprendeu a seguir a série corretamente (143-145), e quando A dá uma ordem a B, ele pode pensar em várias aplicações diferentes, assim, não está determinado na fórmula uma aplicação particular. Assim, em 146, Wittgenstein retoma a argumentação de 140 e 141: que podemos pensar em mais de uma aplicação de uma fórmula algébrica (ou de métodos de projeção de um cubo); lembrando que em 140, a natureza do erro de conceber que o uso era determinado pela palavra estava em apensar que a imagem força uma aplicação particular do uso. Mas logo questiona o interlocutor: quão longe o aluno precisa ir continuando a série corretamente para podermos afirmar que ele é capaz disso? Claramente você não pode determinar um limite aqui. Como posso dizer que entendo a série, conhecendo a série em alguns casos (sem realmente lembrar uma aplicação particular) sem ter como realmente desenvolvê-la (infinitamente)? Então, no que consiste o conhecimento de tal aplicação? O problema parece estar relacionado à questão que vimos anteriormente sobre a diferença do uso em um instante e no tempo (138-9). “Quando você conhece aquela aplicação?” Eu sei sempre ou somente quando penso na série de regras? Se a aplicação da regra é o uso, e esse se dá no tempo, ou a frase "Agora eu entendo!" não pode ser dita, ou tem uma fórmula! No parágrafo 150 Wittgenstein tenta dissolver confusões explicitando que a gramática das palavras "conhecer", "poder" e "ser capaz de" estão intimamente relacionadas, bem como da palavra compreender: "nós dizemos 'Agora eu sei!', - e similarmente, 'Agora eu posso fazer isso!' e 'Agora eu entendo!"” (151). "A" guia "B" escrevendo parte da série e de repente "B"diz “Agora eu entendo!". Quando eu compreendo o sistema uma fórmula ocorre para mim, "Agora eu entendo!" seria algo como o processo que ocorre por trás ou lado a lado de se falar a fórmula (154)? Algo mais do que a fórmula tem que ocorrer para o aluno, pois a série pode ocorrer a ele, entretanto ele não entender o que deve fazer. Wittgenstein ainda se dedica a procurar um processo mental que poderia estar escondido na compreensão, o que não parece possível (153). Em suma, o autor rejeita a ideia de que a compreensão seja um processo mental e alega que pensar assim só gera confusões. Para Wittgenstein, são as circunstâncias sob as quais temos uma experiência que garantem dizermos nesse caso que entendemos. 


\section{Conclusão}

Como pudemos notar, os parágrafos explorados nessa comunicação preparam terreno para o debate sobre regras (192-242). A discussão sobre a frase "As coisas são assim", bem como o jogo de linguagem "seguir uma série" já colocam em questão a temática da regra: a proposição segue a regra "o que pode ser perguntado verdadeiro ou falso"; e "B" segue a série segundo uma regra. Assim, quando falamos de uma recusa da determinação de uma proposição ou de uma aplicação da fórmula, estamos inseridos no debate sobre recusa de determinação do uso pela regra. Não obstante, nesses parágrafos propedêuticos, essa recusa aparece, principalmente a partir da investigação do termo "verstehen" (entender), sob a problematização da concepção de ajuste e o argumento da possibilidade de se pensar em vários métodos de projeção ou fórmulas algébricas. $\mathrm{O}$ que faz com que o autor chegue a conclusões como: a proposição só assume um emprego, porque está inserida nos usos cotidianos e, a partir do conhecimento desse emprego eu posso ajustar ${ }^{6}$ o seu uso, ademais, a aplicação de uma fórmula se dá pelo ajuste de um emprego obtido na experiência ${ }^{7}$. Logo, minha intenção é sistematizar de que maneira argumentos e conclusões que aparecem nesse preâmbulo são retomados no debate sobre regras e/ou como podem ajudar a esclarecê-lo.

\section{Bibliografia}

WITTGENSTEIN, L. Philosophische Untersuchungen, Philosophical Investigations. 4nd ed., Oxford: Blackwell, 2009.

\footnotetext{
${ }^{6} \mathrm{Na}$ discussão apresentada na página 3 , o problema com o uso da uma palavra ajuste é seu distanciamento do emprego cotidiano da linguagem.

${ }^{7} \mathrm{Na}$ discussão apresentada na página 3, o problema com o uso da uma palavra ajuste é seu distanciamento do emprego cotidiano da linguagem.
} 